PAPER

\title{
The effects of water ingestion on orthostatic hypotension in two groups of chronic autonomic failure: multiple system atrophy and pure autonomic failure
}

\section{T M Young, C J Mathias}

J Neurol Neurosurg Psychiatry 2004;75:1737-1741. doi: 10.1136/jnnp.2004.038471

See end of article for authors' affiliations aus

Correspondence to: DrT M Young, Neurovascular Medicine Unit, Imperial College London at St. Mary's Hospital, 2nd Floor, Queen Elizabeth The Queen Mother Wing, Praed Street, London W2 INY, UK; tim.young@ imperial.ac.uk

Received 6 February 2004 Revised 10 March 2004 Accepted 10 March 2004
Background: Oral ingestion of water increases seated blood pressure in patients with chronic autonomic failure by mechanisms that remain unclear. As orthostatic hypotension is common in chronic autonomic failure, and is not always adequately controlled by medication, the potential benefits of water ingestion on standing blood pressure were studied in two types of autonomic failure: multiple system atrophy (MSA), in which the lesion is central and pre-ganglionic, and pure autonomic failure (PAF), in which the lesion is post-ganglionic.

Methods: In 14 patients with autonomic failure (seven PAF and seven MSA) standing blood pressure and heart rate were measured before, and 15 and 35 minutes after ingestion of $480 \mathrm{ml}$ distilled water. Patients remained seated for 15 minutes after water ingestion, with beat to beat cardiovascular indices measured with the Portapres II device with subsequent Modelflow analysis.

Results: Standing prior to water ingestion caused a significant fall in blood pressure in all patients. After water ingestion there was a rise in seated blood pressure. Seated and standing blood pressure at 15 and 35 minutes after water ingestion was significantly higher than before water, with an improvement in orthostatic symptoms. The time to first significant rise in seated blood pressure occurred at 5 minutes post water ingestion in PAF and at 13 minutes in MSA. These increases were accompanied by increases in total peripheral resistance, reaching significance by 5 minutes in PAF and 13 minutes in MSA. There were no significant changes in cardiac output, stroke volume, or ejection fraction.

Conclusions: Water is thus beneficial in improving standing BP in AF, acting within 15 minutes in both MSA and PAF. The earlier onset of the pressor effect in PAF may reflect the differing lesion site and underlying pathophysiology between these conditions. l ngestion of water increases seated blood pressure (BP) in chronic autonomic failure. ${ }^{1}$ This pressor effect first occurs between 5 and 15 minutes after water ingestion, reaches a peak effect at about 30-35 minutes, and lasts for just under an hour. The volume of water ingested influences the pressor response, with $480 \mathrm{ml}$ producing greater effect than $240 \mathrm{ml}$, but the temperature $\left(9^{\circ} \mathrm{C}\right.$ and $\left.24^{\circ} \mathrm{C}\right)$ of ingested water does not seem to be an important factor. ${ }^{2}$ Although the underlying mechanisms of the pressor action of water in AF have not previously been determined, possible mechanisms include partial residual sympathetic activity, baroreflex dysfunction, gastric distension, or fluid redistribution. Multiple system atrophy (MSA) and pure autonomic failure (PAF) provide contrasting models of chronic autonomic failure. In MSA the underlying lesion site is central and pre-ganglionic, whilst in PAF it is distal and post-ganglionic. ${ }^{3}$ The detailed haemodynamic response to water ingestion while seated has been studied in $\mathrm{PAF}^{4}{ }^{4}$ but there have been no comparisons with MSA. We postulated that differences in the pressor response to water between the two groups would relate to the different lesion site in PAF and MSA, and might provide information on the mechanism of the pressor effect.

Orthostatic hypotension $(\mathrm{OH})$ is common to both PAF and MSA, may cause substantial symptoms, and often is inadequately controlled by medication. We determined whether water ingestion would improve standing BP and also symptoms in these patients. Previous work has suggested that $\mathrm{OH}$ in chronic autonomic failure is improved 35 minutes after ingestion of $480 \mathrm{ml}$ of water, although the effects on symptoms are not known. Water increases seated BP 5-15 minutes after ingestion, raising the possibility of an earlier improvement in $\mathrm{OH}$. We therefore measured standing BP 15 and 35 minutes after water ingestion in our subjects.

\section{SUBJECTS AND METHODS}

A total of 14 patients with chronic autonomic failure (seven MSA, seven PAF) were studied. The mean (SD) age of the MSA patients was 62 (9.5) (four males, three females) and that of the PAF patients 59 (10) (three males and four females). MSA and PAF were diagnosed using existing criteria. $^{56}$ All patients had documented sympathetic and parasympathetic dysfunction with severe orthostatic hypotension (table 1). PAF had greater supine BP than MSA. There were no differences in the vasoactive medication between the two groups: three in each were on fludrocortisone and two in each on ephedrine, one PAF took midodrine and two subjects in each group were on no medication. None of the subjects was on anti-parkinsonian medication. Vasoactive medication was withdrawn the night prior to the study. All patients gave informed consent to participate in the study. The study had ethical approval from the National Hospital for Neurology \& Neurosurgery and St Mary's Hospital.

\section{Study design}

On the morning of the study the patients fasted after a light breakfast at 0800 . The study took place in a dedicated

Abbreviations: BP, blood pressure; $\mathrm{CO}$, cardiac output; $\mathrm{DPB}$, diastolic BP; MSA, multiple system atrophy; $\mathrm{OH}$, orthostatic hypotension; PAF, pure autonomic failure; SBP, systolic blood pressure; SV, stroke volume; TPR, total peripheral resistance 
Table 1 Autonomic function testing on study patients

\begin{tabular}{lccc}
\hline & MSA $(\mathbf{n}=7)$ & PAF $(\mathbf{n}=7)$ & $\begin{array}{c}\text { Normal } \\
\text { range }\end{array}$ \\
\hline Supine SBP & $139.4(24.0)$ & $157.4(25.0)$ & \\
Standing SBP & $99.4(16.9)$ & $96.9(33.3)$ & \\
Change in SBP & & & \\
$\quad$ Standing & $-40.0(28.0)$ & $-60.1(25.0)$ & $<-20$ \\
$\quad$ Hand grip & $6.2(5.2)$ & $7.0(5.9)$ & $\geqslant 17$ \\
$\quad$ Cold pressor & $8.7(19.0)$ & $2.6(6.9)$ & $\geqslant 15$ \\
Supine DBP & $82.0(11.2)$ & $86.9(9.7)$ & \\
Standing DBP & $6(12.7)$ & $52.7(11.3)$ & \\
Change in DBP & & & \\
$\quad$ Standing & $-22.3(16.1)$ & $-33.4(8.5)$ & $<-10$ \\
$\quad$ Hand grip & $4.2(7.1)$ & $0.7(6.4)$ & $\geqslant 11$ \\
$\quad$ Cold pressor & $5.3(10.1)$ & $-0.7(2.7)$ & $\geqslant 10$ \\
Sinus arrythmia ratio & $1.11(0.05)$ & $1.06(0.06)$ & $>1.2$ \\
\hline
\end{tabular}

Values are mean (SD) for MSA and PAF.

$\mathrm{SBP}$, systolic blood pressure; DBP, diastolic blood pressure.

autonomic laboratory between 1000 and 1300. The patients emptied their urinary bladders. They were then seated, and BP was recorded both intermittently and continuously. Intermittent brachial BP values were obtained every 3 minutes using an automated Dynamap (Critikon) sphygmomanometer on the left arm. Continuous measurement of beat to beat BP was obtained throughout the study with the Portapres II device on the middle finger of the right hand. Subsequent calculation of cardiac output (CO), total peripheral resistance (TPR), and stroke volume (SV) using Modelflow analysis was made. This has previously been validated at rest and in relation to stimuli such as head up tilt. $^{7-11}$ After 30 minutes of baseline recordings, the patient stood for 5 minutes (Stand 0), and brachial BP was recorded 3 and 5 minutes after standing up. The patient then returned to the seated position. Following standing the patient was questioned on the presence and severity of orthostatic symptoms. After baseline BP had been re-established, the patient drank $480 \mathrm{ml}$ of distilled water at room temperature within a target time of 5 minutes (mean time taken by the MSA patients was 3 minutes 47 seconds, and by the PAF patients 3 minutes 4 seconds; no significant difference between groups). On completion of water ingestion the patient remained seated for a further 15 minutes. The patient then stood in an identical manner to Stand 0; this was termed Stand 1, the first after water ingestion. On completion of Stand 1, the patient returned to the seated position for a further 15 minutes. After this time (now 35 minutes after water ingestion) the patient stood for 5 minutes (Stand 2) in an identical manner to the previous stands. During each episode of standing hypotensive symptoms were assessed ${ }^{6}$

\section{Data analysis}

Dynamap values for systolic and diastolic BP (SBP, DBP) were compared at 3 and 5 minutes into each stand before and after water. Patients acted as their own controls with BPs for stands 1 and 2 being compared with their own Stand 0 values. Paired Student's $t$ test was used, with statistical significance being taken as $\mathrm{p}<0.05$.

\section{RESULTS}

\section{Pooled dynamap data for all 14 patients, before and during standing}

The 14 AF subjects showed a significant fall in SBP and DBP (Dynamap data) on standing compared with seated values. There was no significant change in the drop on standing after water ingestion, but, as seated SBP and DBP rose significantly over this time, the net result was a significant increase in standing SBP and DBP at both 15 and 35 minutes after
Table 2 Dynamap blood pressure and heart rate in 14 patients with $A F$ (seven MSA, seven PAF) on standing, and before and after ingestion of $480 \mathrm{ml}$ water

\begin{tabular}{|c|c|c|c|}
\hline & $\begin{array}{l}\text { Stand } 0 \text { (before } \\
\text { water) }\end{array}$ & $\begin{array}{l}\text { Stand } 1 \text { (15 } \mathrm{min} \\
\text { after water) }\end{array}$ & $\begin{array}{l}\text { Stand } 2 \text { (35 } \mathrm{min} \\
\text { after water) }\end{array}$ \\
\hline \multicolumn{4}{|c|}{ Seated value just prior to stand } \\
\hline SBP & $110.6(25.1)$ & $122.9(29.0)$ & $133.9(25.5)$ \\
\hline DBP & $69.6(12.9)$ & 76.4 (13.9) & $80.4(14.1)$ \\
\hline HR & 73.7 (11.2) & $70.5(8.6)$ & $70.0(9.7)$ \\
\hline \multicolumn{4}{|c|}{$3 \mathrm{~min}$ of stand } \\
\hline SBP & $79.5(21.5)^{\star *}$ & $101.0(23.3)^{* * *}$ & $99.6(24.0)^{* * *}$ \\
\hline DBP & $51.5(15.0)^{* *}$ & $63.6(13.0)^{* *}$ & $64.0(14.0)^{* *}$ \\
\hline HR & $82.9(15.2)$ & $75.8(13.1)^{\star *}$ & $77.2(13.2)^{\star *}$ \\
\hline \multicolumn{4}{|c|}{$5 \mathrm{~min}$ of stand } \\
\hline SBP & $77.4(25.6)^{* *}$ & $95.3(23.0)^{* *}$ & $95.4(22.9)^{* * *}$ \\
\hline DBP & $49.6(16.3)^{* *}$ & $63.4(16.1)^{* *}$ & $60.4(16.1)^{* *}$ \\
\hline $\mathrm{HR}$ & 81.9 (16.2) & $76.6(14.6)^{* *}$ & $78.9(14.1)$ \\
\hline \multicolumn{4}{|c|}{$\begin{array}{l}\text { SBP, systolic blood pressure; DBP, diastolic blood pressure; HR, heart } \\
\text { rate. } \\
\text { Values are } \mathrm{mmHg}(\mathrm{SD}) \text { for } \mathrm{BP} \text { and beats/min (SD) for HR: Stand } 1 \text { and } 2 \\
\text { compared with Stand } 0 . \\
{ }^{*} \mathrm{p}<0.05 ;{ }^{* *} \mathrm{p}<0.01 ;{ }^{* * *} \mathrm{p}<0.001 \text {. }\end{array}$} \\
\hline
\end{tabular}

water ingestion compared with baseline. These results are shown in table 2 .

\section{Pooled beat to beat data for all 14 patients, before and during standing}

Mean seated baseline values for all 14 subjects were compared with mean values for the 5 minute stands before and after water. Mean (SD) pre-stand values of 103.3 (35.5)/ 60.9 (19.3) showed a significant drop on Stand 0 to 79.4 (30.0)/48.5 (19.5) (table 3). As with the Dynamap data, a significant increase in standing SBP and DBP compared with Stand 0 was seen during both periods of standing after water. Standing SBP for Stand 1 was 99.0 (25.0)/61.0 (16.9), and for Stand 2 was $103.3(29.8) / 64.9$ (19.5). As for the seated baseline, there was an increase in TPR in each stand after water, although this did not reach significance. In addition, there was a smaller increase in $\mathrm{CO}$, which also failed to reach significance.

\section{Symptoms experienced on standing}

After standing on each occasion the subjects were questioned about the presence and severity of three common symptoms of $\mathrm{OH}$ : light headedness, visual disturbance, and "coat hanger" neck pain in the occipital and shoulder region. ${ }^{6}$ Of the 14 subjects, 11 reported one or more of these symptoms during Stand 0. All 11 of the subjects symptomatic on Stand 0 noted subjective improvement in their orthostatic symptoms during Stands 1 and 2. The three subjects (two MSA and one PAF) who experienced no symptoms during Stand 0 remained without symptoms during both subsequent standing periods.

\section{Subset analysis (MSA and PAF data) Dynamap data}

Baseline seated BP did not differ significantly between MSA (117.3 (18.6)/73.0 (13.8) mmHg) and PAF (103.9 (30.1)/66.3 (11.9)), as shown in table 4 . Stand 0 resulted in a significant drop in BP at 3 and 5 minutes in both MSA and PAF, with no significant difference between the groups. Subgroup analysis showed a similar increase in standing BP after water ingestion in both groups of patients (table 4), with no significant difference between the groups.

\section{Beat to beat haemodynamic data}

Beat to beat data was assessed before and during the 15 minutes immediately following water ingestion, during 
Table 3 Beat to beat haemodynamics in MSA and PAF on standing, before and after water

\begin{tabular}{|c|c|c|c|c|c|c|}
\hline & Seated & Stand 0 & Seated & Stand 1 & Seated & Stand 2 \\
\hline \multicolumn{7}{|l|}{ MSA } \\
\hline SBP & $102.8(28.9)$ & 93.7 (32.2) & $113.0(28.5)$ & $102.4^{*}(24.6)$ & $118.9(28.2)$ & $108.2^{*}(33.7)$ \\
\hline DBP & $59.7(17.4)$ & $56.6(21.4)$ & $69.0(19.5)$ & $63.3^{*}(17.6)$ & $71.2(19.1)$ & $68.3^{*}(22.4)$ \\
\hline $\mathrm{CO}$ & $5.2(1.7)$ & $4.4(1.3)$ & 4.7 (1.7) & $4.4(0.9)$ & $4.8(2.0)$ & $3.5(1.1)$ \\
\hline TPR & $1.0(0.5)$ & $1.1(0.6)$ & $1.3(0.7)$ & $1.1(0.4)$ & $1.1(0.5)$ & $1.4(0.7)$ \\
\hline SV & $68.7(20.4)$ & 51.7 (17.1) & $63.0(16.8)$ & 54.5 (8.7) & $65.2(19.6)$ & 49.5 (11.1) \\
\hline HR & $76.1(10.2)$ & $87.2(17.6)$ & $74.4(8.6)$ & $81.3(14.9)$ & $72.6(10.5)$ & $82.0(9.4)$ \\
\hline \multicolumn{7}{|l|}{ PAF } \\
\hline SBP & $102.8(67.2)$ & $67.2(23.6)$ & $130.3(39.2)$ & $95.6 * *(26.9)$ & $131.6(40.4)$ & $98.4^{* *}(26.9)$ \\
\hline DBP & $62.1(41.5)$ & 41.5 (15.9) & $77.3(17.7)$ & $58.6^{*}(17.2)$ & $80.0(20.3)$ & $61.5^{*}(17.2)$ \\
\hline $\mathrm{CO}$ & $3.5(1.5)$ & $2.8(0.9)$ & 3.7 (1.9) & $3.5(1.5)$ & $3.6(2.2)$ & $3.3(1.5)$ \\
\hline TPR & $1.7(1.1)$ & $1.3(0.9)$ & $1.8(0.8)$ & $1.6(0.8)$ & $1.9(1.2)$ & $1.7(1.0)$ \\
\hline SV & $47.9(18.5)$ & $38.4(13.8)$ & $53.6(24.5)$ & $49.1(19.0)$ & $52.2(27.6)$ & $45.6(18.2)$ \\
\hline $\mathrm{HR}$ & $72.1(11.2)$ & $76.2(13.3)$ & $67.8(6.1)$ & $71.4(8.0)$ & $67.3(7.3)$ & $71.1(9.4)$ \\
\hline \multicolumn{7}{|c|}{ Pooled data for all 14 patients } \\
\hline SBP & $103.3(35.5)$ & $79.4(30.0)$ & $121.7(34.1)$ & $99.0 *(25.0)$ & $125.2(34.1)$ & $103.3^{*}(29.8)$ \\
\hline DBP & 60.9 (19.3) & $48.5(19.5)$ & $73.1(18.4)$ & $61.0 *(16.9)$ & $75.4(19.4)$ & $64.9 *(19.5)$ \\
\hline $\mathrm{CO}$ & $4.3(1.8)$ & $3.5(1.3)$ & $4.2(1.8)$ & $4.0(1.3)$ & $4.2(2.1)$ & $3.7(1.4)$ \\
\hline TPR & $1.3(0.9)$ & $1.2(0.8)$ & $1.6(0.8)$ & $1.3(0.7)$ & $1.5(1.0)$ & $1.6(0.8)$ \\
\hline SV & $58.3(21.6)$ & 44.6 (16.3) & $58.3(20.8)$ & $51.8(14.5)$ & $58.7(24.0)$ & $47.6(14.6)$ \\
\hline $\mathrm{HR}$ & $74.1(10.5)$ & $81.3(15.8)$ & $71.1(7.9)$ & $76.4^{*}(12.6)$ & $69.9(9.1)$ & $76.6^{*}(12.6)$ \\
\hline
\end{tabular}

Values (SD): Stand 1 and 2 compared with Stand 0.

SBP, systolic blood pressure ( $\mathrm{mmHg})$; DBP, diastolic blood pressure ( $\mathrm{mmHg})$; CO, cardiac output (I/min); TPR, total peripheral resistance (MU); SV, stroke volume $(\mathrm{ml}) ; \mathrm{HR}$, heart rate (beats $/ \mathrm{min})$.

${ }^{*}=p<0.05 ;{ }^{* *}=p<0.01 ;{ }^{* * *}=p<0.001$.

which time the patients remained seated. In PAF an increase in seated SBP and DBP was recorded after water ingestion, which first reached significance 5 minutes post water ingestion (fig 1) and remained so until the end of the study. Seated TPR increased, first reaching significance 5 minutes after water ingestion and remaining so until the end of the study. Seated CO, SV, and EF did not significantly change during the study. There was a non-significant reduction in seated HR (beats/min) over the first 15 minutes post water ingestion in both subsets (mean (SD) baseline 73.5 (10.1) and 78.2 (9.7); 15 minutes post water $67.8(6.1)$ and 74.4 (8.6) for PAF and MSA respectively). Beat to beat data during each stand (table 3 ) showed no significant difference between MSA and PAF.

In MSA, an increase in seated SBP and DBP was recorded after water ingestion, which first reached significance 13 minutes after ingestion (fig 2) and remained so until the end of the study. Seated TPR increased, first reaching significance 13 minutes after water ingestion and remaining so until the end of the study. Seated HR showed a reduction, which failed to reach statistical significance. Seated CO, SV, and EF did not significantly change during the study.

\section{DISCUSSION}

Our results have shown that oral ingestion of $480 \mathrm{ml}$ of distilled water results in subjective and objective improvements in $\mathrm{OH}$ on standing in both MSA and PAF subjects when measurements were made at 15 and 35 minutes after water. In addition the detailed analysis, utilising continuous haemodynamic measurements pre and post water indicate that there are temporal differences in the pressor response between MSA and PAF. In previous studies ${ }^{12}$ there did not appear to be differences, and it may be that intermittent measurements every 3 or 5 minutes may have made comparisons difficult.

The haemodynamic differences between MSA and PAF while seated warrant discussion. In PAF the pressor effect occurred sooner (within 5 minutes) than in MSA (13 minutes after ingestion). This may shed further light on the mechanisms responsible for the pressor response, as in PAF

Table 4 Dynamap blood pressure and heart rate in patients with PAF and MSA on standing, before and after ingestion of $480 \mathrm{ml}$ water

\begin{tabular}{|c|c|c|c|c|c|c|}
\hline & \multicolumn{3}{|l|}{ PAF $(n=7)$} & \multicolumn{3}{|l|}{ MSA $(n=7)$} \\
\hline & $\begin{array}{l}\text { Stand } 0 \\
\text { (before water) }\end{array}$ & $\begin{array}{l}\text { Stand } 1 \text { ( } 15 \mathrm{~min} \\
\text { after water) }\end{array}$ & $\begin{array}{l}\text { Stand } 2 \text { ( } 35 \mathrm{~min} \\
\text { after water) }\end{array}$ & $\begin{array}{l}\text { Stand } 0 \\
\text { (before water) }\end{array}$ & $\begin{array}{l}\text { Stand } 1 \text { ( } 15 \mathrm{~min} \\
\text { after water) }\end{array}$ & $\begin{array}{l}\text { Stand } 2 \text { ( } 35 \mathrm{~min} \\
\text { after water) }\end{array}$ \\
\hline \multicolumn{7}{|c|}{ Seated value just prior to stand } \\
\hline SBP & $103.9(30.1)$ & 126.4 (32.9) & $137.9(30.5)$ & $117.3(18.6)$ & $119.4(26.7)$ & $129.9(21.0)$ \\
\hline DBP & $66.3(11.9)$ & 78.7 (10.8) & $81.1(14.2)$ & 73.0 (13.8) & $74.1(17.0)$ & $79.7(15.1)$ \\
\hline $\mathrm{HR}$ & $71.1(11.4)$ & $66.0(5.2)$ & $65.3(6.8)$ & $76.7(11.1)$ & 75.7 (9.3) & $75.0(10.4)$ \\
\hline \multicolumn{7}{|c|}{$3 \mathrm{~min}$ of stand } \\
\hline SBP & $68.4(18.5)^{\star *}$ & $97.3(25.4)^{*}$ & $96.9(26.2)^{*}$ & $90.6(19.5)^{* *}$ & $106.0(22.2)^{\star *}$ & $102.3(23.6)^{*}$ \\
\hline DBP & $43.4(10.7)^{\star *}$ & $61.0(16.3)^{*}$ & $63.3(16.0)^{* *}$ & $59.6(14.8)^{* *}$ & $66.3(10.4)$ & 64.7 (13.0) \\
\hline HR & $77.0(13.9)$ & $69.7(8.2)^{*}$ & $69.9(8.1)^{*}$ & $89.8(14.6)$ & $82.8(14.8)^{*}$ & $85.8(14.7)$ \\
\hline \multicolumn{7}{|c|}{$5 \mathrm{~min}$ of stand } \\
\hline SBP & $64.4(20.8)^{\star *}$ & $88.9(22.5)^{\star}$ & $92.1(25.1)^{* *}$ & $90.3(24.5)^{\star *}$ & $101.7(23.3)^{*}$ & $98.6(21.9)^{\star *}$ \\
\hline DBP & $40.4(12.1)^{* *}$ & $59.4(16.5)^{*}$ & $57.7(17.2)^{*}$ & $58.9(15.2)^{* *}$ & $67.3(15.9 * *)$ & $63.0(15.9)^{*}$ \\
\hline $\mathrm{HR}$ & $75.1(13.1)$ & $69.1(8.9)$ & 70.7 (8.8) & 89.8 (16.8) & $85.3(15.7)^{*}$ & 88.5 (13.5) \\
\hline
\end{tabular}



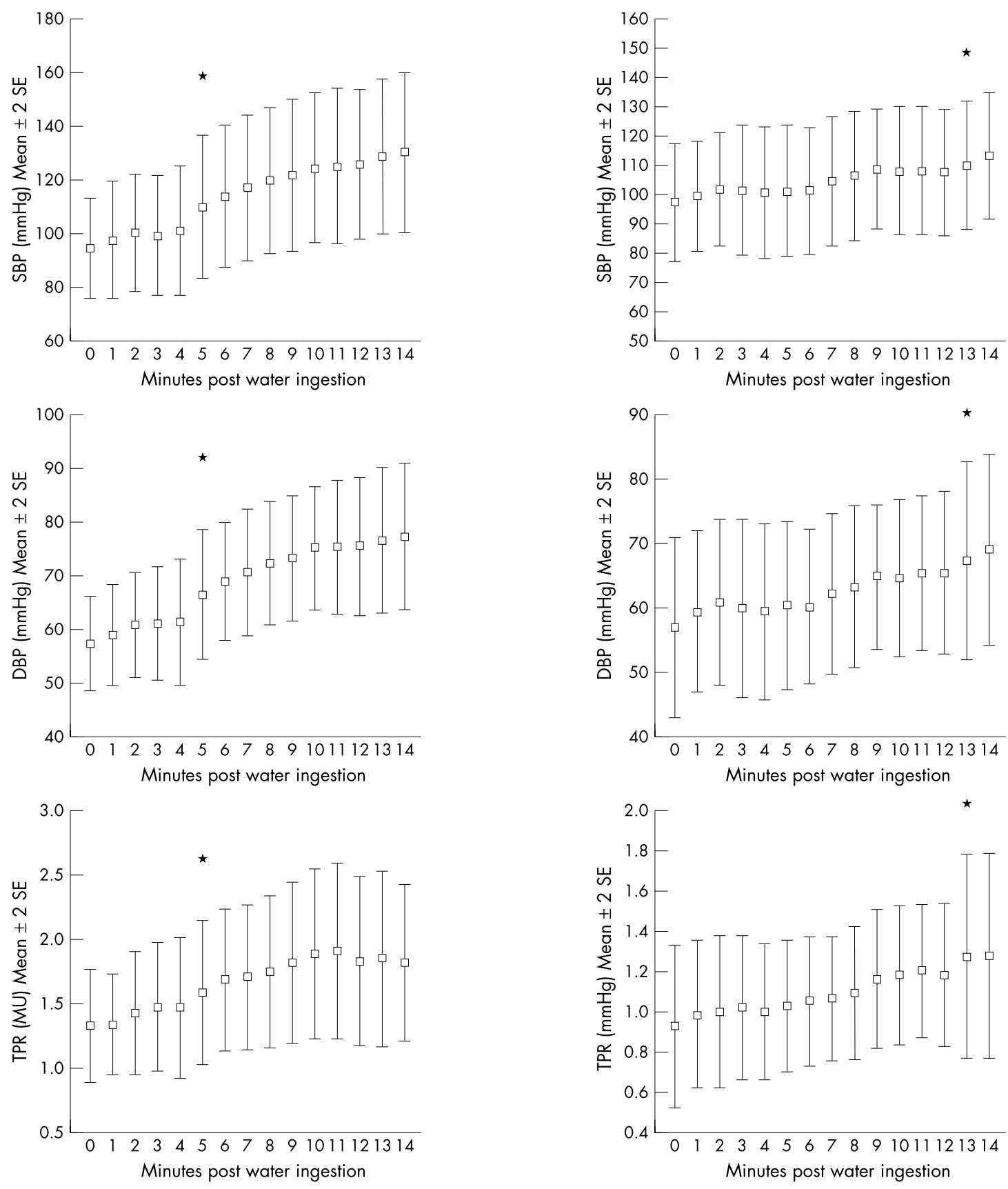

Figure 1 Seated beat to beat haemodynamics in PAF during the first 15 minutes post water ingestion. Upper left panel, systolic BP (SBP); upper right panel, diastolic BP (DBP); lower panel, total peripheral resistance (TPR); " $O$ " minutes = mean baseline seated value. "First significant increase compared with baseline.

all the subjects had clear evidence of substantial peripheral sympathetic denervation, whereas in MSA the predominant lesion was likely to be preganglionic. The pressor response to water is known to be dependant on the volume ingested, and may be the result of gastric distension increasing sympathetic nerve activity by reflex mechanisms, as has been described in normal subjects. ${ }^{13}$ This response is likely to be dependent on residual sympathetic activity, and is therefore expected to be minimal in PAF and greater in MSA. This would be consistent with the effects previously described of yohimbine, an $\alpha_{2}$ agonist that is dependent on sympathetic activity, and where the pressor response was related to the pressor response of water. ${ }^{2}$ However, this was not the case in our

Figure 2 Seated beat to beat haemodynamics in MSA during the first 15 minutes post-water ingestion. Upper left panel, systolic BP (SBP); upper right panel, diastolic BP (DBP); lower panel, total peripheral resistance (TPR); " 0 " minutes = mean baseline seated value. "First significant increase compared with baseline.

study, as the response was as great in PAF, and had a more rapid onset than in MSA. An alternative may be that the pressor response in PAF was related to denervation supersensitivity, which has been well documented in this group, and is greater than in MSA. ${ }^{3}$ It is possible that in PAF, even a small amount of NA released could have acted on supersensitive receptors, although this seems less plausible than the release of other vasoconstrictor substances, including factors such as endothelin, which may then exert the pressor response. These possibilities may explain the rise in peripheral resistance found in this study. A further substance to be considered is vasopressin, which is known to be released in PAF but not MSA during the head up position. ${ }^{14}$ 
Another factor to be considered with water ingestion is the effect of fluid repletion, in patients who are known to be prone to salt and water loss, especially when they are recumbent. ${ }^{15}$ It may be that in MSA there is greater disruption of vasopressin secretion, rendering them even more fluid depleted. It is conceivable that the longer time taken to reach a pressor response in MSA was a reflection of greater intra and extravascular fluid depletion. It is not clear how quickly after ingestion water is absorbed from the gut in MSA or PAF and in particular how much would have been absorbed in PAF within 5 minutes after ingestion, when the pressor effect of water first occurred.

These studies therefore indicate that although the magnitude of pressor response is similar in PAF and MSA, there are differences in the speed of response. The reasons for this could be multiple, and need to be investigated further.

In both PAF and MSA, water increased the standing BP as compared with baseline, and reduced symptoms due to $\mathrm{OH}$. In previous studies in autonomic failure, orthostatic challenge was compared at 35 minutes only after water ingestion; in our subjects we predicted that the beneficial response on standing might occur earlier, as in previous studies in PAF the seated pressor response was observed within 5 minutes of water ingestion. The haemodynamic analysis indicated that the pressor response was associated with an increase in TPR, again favouring vasoconstrictor mechanisms as being responsible. However, the increase in standing BP appeared to be related to the increase in baseline $\mathrm{BP}$ after water rather than to increased sympathetic nerve activation following water, as the differences in absolute falls of BP following standing at 15 and 35 minutes post-ingestion were similar to those found at baseline. Regardless of the mechanisms, water improved symptoms in all the patients who had been symptomatic prewater ingestion. Thus, water ingestion may be a valuable adjunct in the management of $\mathrm{OH}$, especially in the morning when patients are usually most affected by $\mathrm{OH}$.

\section{ACKNOWLEDGEMENTS}

This study was supported by a grant from the Sarah Matheson Trust Autonomic Disorders Association.

\section{Authors' affiliations}

T M Young, Neurovascular Medicine Unit, Faculty of Medicine, Imperial College London at St.Mary's Hospital

C J Mathias, Autonomic Unit, Institute of Neurology, the National Hospital for Neurology and Neurosurgery, Queen Square, University

College London, London, UK

Competing interests: none declared

\section{REFERENCES}

1 Jordan J, Shannon JR, Grogan E, et al. A potent pressor response elicited by drinking water. Lancet 1999;353:723.

2 Jordan J, Shannon JR, Black BK, et al. The pressor response to water drinking in humans: a sympathetic reflex? Circulation 2000;101:504-9.

3 Polinsky in Mathias CJ, Bannister R. Autonomic failure. A textbook of clinical disorders of the autonomic nervous system, 4th edn. Oxford: Oxford University Press, 2002

4 Cariga P, Mathias CJ. Human sympathetic denervation due to autonomic failure. Clin Sci 2001;101:313-19.

5 Gilman S, Low PA, Quinn N, et al. Consensus statement on the diagnosis of MSA. Clin Auton Res 1998:8:359-62.

6 Mathias CJ. Disorders of the autonomic nervous system. In: Bradley WG, Daroff RB, Fenichel GM, Jankovic J, eds. Neurology in clinical practice, 4th edn. Boston, USA: Butterworth-Heinemann, 2004.

7 Harms MP, Wesseling KH, Pott F, et al. Continuous stroke volume monitoring by modelling flow from non-invasive measurement of arterial blood pressure in humans under orthostatic stress. Clin Sci 1999;97:291-301.

8 Jellema WT, et al. Continuous cardiac output in septic shock by simulating a model of aortic impedance. Anaesthesiology 1999;90:1317-28.

9 Jellema WT, Imholz BP, KH, et al. Estimation of beat-to-beat changes in stroke volume from arterial pressure Clin Auton Res 1999;9:185-92.

10 Langewouters GJ, Settels JJ, Roelandt R, et al. Why use Finapres or Portapres rather than intra-arterial or intermittent non-invasive techniques of blood pressure measurement? Med Eng Technol 1998;22:37-43.

11 Voogel AJ, van Montfrans GA. Reproducibility of twenty-four hour finger arterial pressure, variability and systemic haemodynamics. J Hypertens 1997; 15:1761-5.

12 Shannon JR, Diedrich A, Biaggioni I, et al. Water drinking as a treatment for orthostatic syndromes. Am J Med 2002:355-60.

13 Rossi P, Andriesse Gl, Oey PL, et al. Stomach distension increases efferent muscle sympathetic nerve activity and blood pressure in healthy humans. J Neurol Sci 1998;161:148-55.

14 Kaufmann $\mathrm{H}$, et al. Upright tilt seems to increase vasopressin in Pure autonomic failure not multiple system atrophy. Neurology 1992;2:590-3.

15 Mathias CJ, Fosbraey P, da Costa DF, et al. The effect of desmopressin on nocturnal polyuria, overnight weight loss and morning postural hypotension in patients with autonomic failure. BMJ 1986;293:353-4. 